\title{
Newborn Survival in India - Challenges and Priorities for Andhra Pradesh
}

\author{
Usha Rani $T^{\star}$, Venkateswara Rao Jampana and Vasudeva Murali Machiraju
}

Department of Pediatrics, Gandhi Medical College, Hyderabad, India

*Corresponding author: T. Usha Rani, Associate Professor, Gandhi Medical College, Paediatrics, 6-1-339/8/A, Padmarao Nagar, Secunderabad, Hyderabad, Andhra Pradesh 500025, India, Tel: 09849066216; Fax: 04027505566; E-mail: dr.thotausha@gmail.com

Rec date: Mar 22, 2014; Acc date: Jun 28, 2014; Pub date: Jun 30, 2014

Copyright: @ 2014 Rani TU, et al. This is an open-access article distributed under the terms of the Creative Commons Attribution License, which permits unrestricted use, distribution, and reproduction in any medium, provided the original author and source are credited.

\begin{abstract}
Around a quarter of global neonatal deaths. According to Sample Registration Survey (SRS) 2009 report neonatal mortality contributes to about two thirds of all infant deaths and about half of all under five deaths in the country. The state of Andhra Pradesh has a Neonatal mortality rate of 33/1000 live births. The major challenge for the state of Andhra Pradesh has been a stagnating Infant Mortality Rate at 53/1000 Live Births (National Family Health Survey-3), $70 \%$ of which is contributed by Neonatal Mortality. The common causes responsible for newborn deaths are sepsis $(50 \%)$, prematurity \& low birth weight $(35 \%)$ and birth asphyxia $(23 \%)$. Maternal healths in general and perinatal care in particular are important determinants of neonatal survival. Maternal malnutrition, inadequate antenatal care, high proportion of unsupervised home deliveries, suboptimal care during institutional deliveries and high proportion of low birth weight newborns are other factors responsible for high neonatal mortality. We need to have a well designed programme with specific objectives and timeframes with a fast track approach to improve the New born survival. A well designed package of interventions, ranging from the immediate priority of providing quality neonatal services to a long term approach targeted to improve the health status of the girl child is the need of the hour. Improving quality of life, provision of universal access to healthcare, strengthening health care systems, creating perinatal/neonatal centres of excellence in all Government medical colleges are highly essential to improve the newborn care. Effective utilization of Information technology to network peripheral health centres with tertiary centres will facilitate mentoring and supportive supervision for better outcomes.
\end{abstract}

Keywords: Maternal malnutrition; Neonatal mortality rate; Perinatal care

\section{Introduction}

Globally, one of the major challenges in health sector has been an unacceptably high neonatal mortality. Only five countries account for more than half of the world's 3.3 million newborn deaths - India, Nigeria, Pakistan, China and Democratic Republic of Congo [1]. India carries the highest single share of neonatal deaths in the world and contributes to around a quarter of global neonatal deaths (Figure 1) [2]. Of the 26 million babies born in India every year nearly one million babies die before the age of one month. According to SRS 2009 report, neonatal mortality (Neonatal Mortality Rate - 34/1000 live births) contributes to about two thirds of all infant deaths (Infant Mortality Rate - 50/1000 live births) and about half of all under five deaths in the country (Under Five Mortality Rate- 64/1000). 56 per cent of all newborn deaths in INDIA occur in five states: Uttar Pradesh, Madhya Pradesh, Bihar, Rajasthan and Andhra Pradesh (Figure 2).

\section{Status of Newborn Health in Andhra Pradesh}

The state of Andhra Pradesh has Neonatal mortality rate of 33/1000 live births. Around 50,000 babies die in this state every year. The major challenge for the state of Andhra Pradesh has been a stagnating Infant Mortality Rate at 53/1000 Live Births (NFHS-3), 70\% of which is contributed by Neonatal Mortality [3]. Most of the newborn deaths occur in the first one week of life [3]. There is a huge urban to rural difference in the death rates. The neonatal mortality in rural areas is almost two times that of urban areas.

\section{Factors Responsible for High Neonatal Mortality}

The common causes responsible for newborn deaths are sepsis (50\%), prematurity, low birth weight (35\%) and birth asphyxia (23\%) [4]. Low birth weight directly or indirectly contributes to $60-80 \%$ of the neonatal deaths. All these causes influenced by perinatal care. Maternal health in general and perinatal care in particular is important determinants of neonatal survival. Neonatal outcomes are affected by health throughout the girl child's lifecycle, starting from infancy through adolescence and pregnancy.

The health of pregnant women is an integral part of human survival as life starts from the mother's womb and it is the intrauterine environment that shapes up the health of new off-spring [5]. There are several misconceptions on consumption of various nutritious foods during pregnancy in different Indian societies. Some of these beliefs result in poor nutritional status of pregnant women as high calorie and protein rich foods are needed during pregnancy. In addition, maternal anemia and infections during pregnancy are often associated with high neonatal mortality due to low birth weight, prematurity and sepsis. The incidence of maternal anemia is as high as $50 \%$ in most of the Indian states [6]. Apart from the above biological factors, young age at marriage, frequent child-bearing, unplanned motherhood and abortions result in poor nutritional status of women and poor survival rates of children $[7,8]$. High proportion of unsupervised home deliveries suboptimal care during institutional deliveries, high proportion of low birth weight newborns, delayed initiation of breast feeding and lack of awareness regarding warm care for the newborns are other factors responsible for high neonatal mortality [3].

An assessment of Neonatal units of the state of Andhra Pradesh by the state Government and UNICEF in the year 2011 had shown that 
only 2 out of 14 existing Newborn Units in the state are fully fledged sanctioned units. The available infrastructure, staff and equipment in most of these units is not consistent with the standards recommended by National Neonatology Forum of INDIA [9] and is grossly disproportionate to the patient load. There was overcrowding in all the facilities. On the other hand, there is a very robust private health sector in this state providing level II and level III neonatal care especially in cities like Hyderabad, Vijayawada and Vishakhapatnam [10].

\section{Strategies to Improve Newborn Survival}

To improve New born survival we need to have a well-designed programme with specific objectives and timeframes with a fast track approach. A well designed package of interventions, ranging from the immediate priority of providing quality neonatal services to a long term approach targeted to improve the health status of the girl child is the need of the hour.

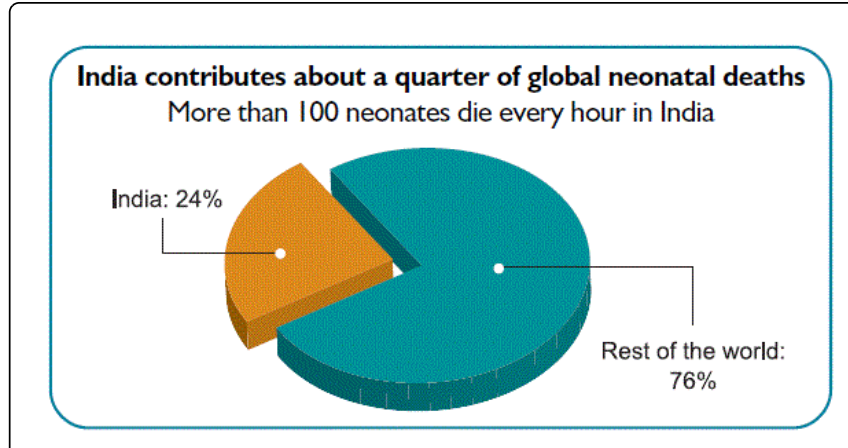

Figure 1: The Lancet 365, Issue 9474

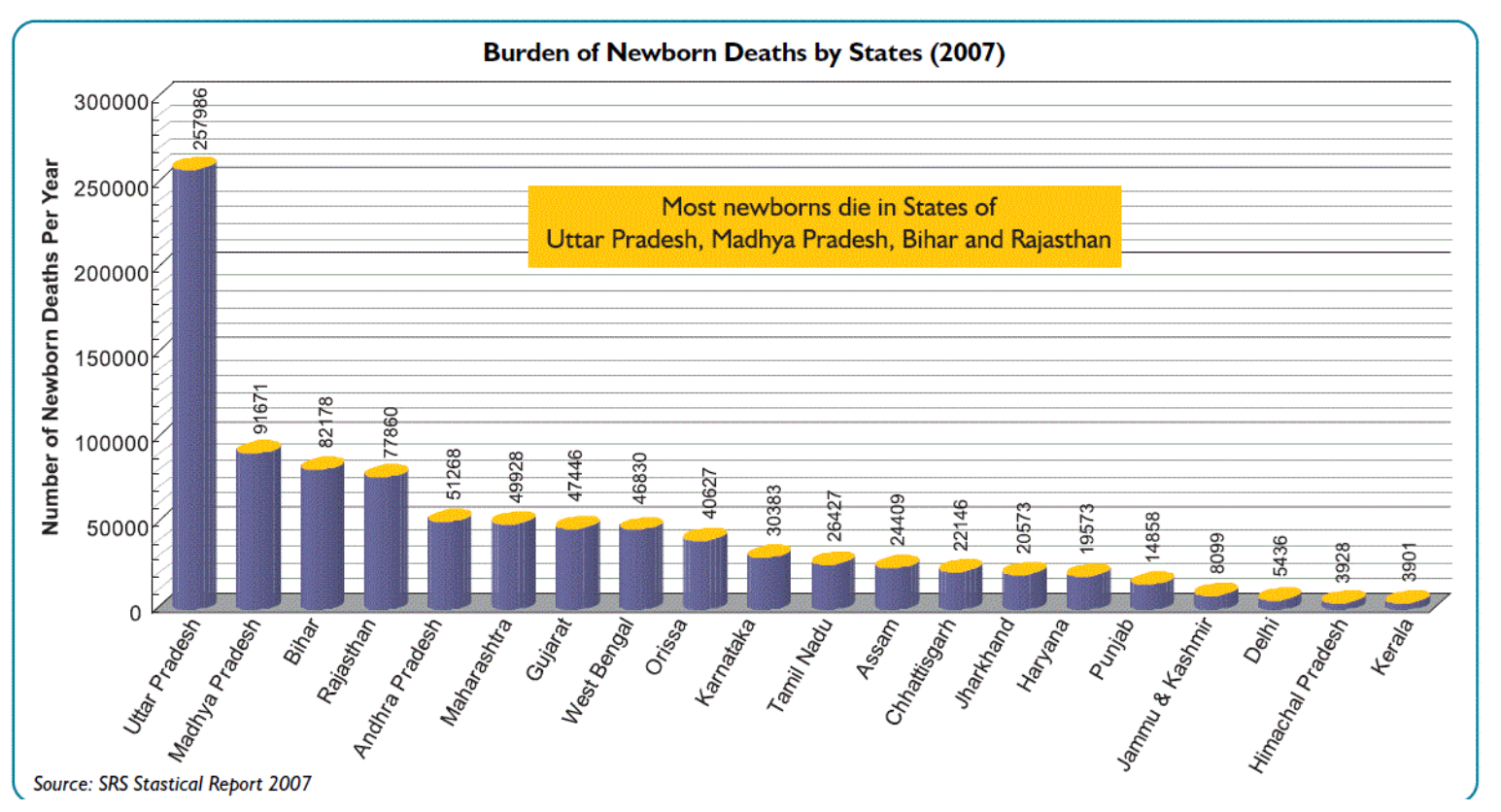

Figure 2: Neonatal Mortality in different states of INDIA

Under National Rural Health Mission (NRHM) a three tier system of newborn care has been planned and is being implemented all over the country which includes establishment of 1).Newborn Care Corners (NBCCs) in all Primary health centres to provide routine care to all the babies and for prompt referral of sick babies. II). Newborn Care Corners in labour Rooms \& Operation Thetres and Newborn stabilization (NBSUs) units in all the community health centres where sick babies can be stabilized. III). Newborn Care Corners in labour Rooms \& Operation Theatres and Special Newborn Care Units (SNCUs) in all the District and Medical college hospitals [10].

Government of Andhra Pradesh has taken various initiatives to overcome the challenge of high neonatal mortality by strengthening the maternal and newborn health care delivery services in a bigway. Janani suraksha yojana (JSY-funded by Govt of INDIA) and sukhibahava scheme (funded by state govt.,) aim at encouraging the rural BPL (Below Poverty Line) women to approach government institutions for deliveries, to limit the number of pregnancies to two, and to enhance the age of child bearing to 19 yrs by giving Rs1000 cash incentive per delivery [3]. In addition, Janani Shishu Suraksha Karayakram (JSSK) provides for completely free and cashless services to pregnant women (including normal \& caesarean deliveries) and sick new born care in Government health institutions in both rural and urban areas.

Institutional deliveries in Andhra Pradesh have increased from 12.78 lakhs (2006-2007) to 14.2 lakhs (2008-09). Two districts are implementing Integrated Management of Neonatal and Childhood Illnesses (IMNCI) approach for managing common and 1,555 Medical officers were trained in IMNCI approach so far. The state of Andhra Pradesh has pioneered the Emergency Management and Research Institute (EMRI-108) referral transport system facilitating quick transport of pregnant women and sick newborns from their homes to health facilities [3]. 


\section{Academic Initiatives and Strengthening of Institutions}

Andhra Pradesh Government in collaboration with Dr NTR University of Health sciences has initiated implementation of inclusion of Integrated Management of Neonatal and childhood Illnesses in undergraduate medical and nursing curriculum to empower the young medical and nursing graduates with skills to manage neonatal illnesses in an effective manner. All the medical and nursing professionals in the government health care system are being trained in newborn care programmes like Navajat sishu suraksha yojana (NSSK), and Facility based newborn care (FBNC).

Our government had also accorded sanction for 44 special newborn care units (SNCUs),

156 NBSUs (Newborn stabilization Units), 1372 NBCC (Newborn Care Corners). These are being established in accordance with the standard guidelines and will become operational very soon. The impact will be visible in the years to come. There is an urgent need to upgrade the facilities in Medical college hospitals as centres of excellence for training and service delivery. Establishing sanctioned neonatal units will be a step in right direction as it will facilitate provision of budget for staff and equipment on a permanent basis.

\section{Role of Breastfeeding in Improving Newborn Survival}

Early initiation of breastfeeding benefits both mothers and newborns. This could be facilitated by placing the newborn skin-toskin on the mother's chest, which would also prevent hypothermia, promotes bonding, and reduces the mother's risk of haemorrhage. Colostrum provides protective antibodies and essential nutrients. Exclusive breastfeeding for six months as the sole intervention was shown to decrease the mortality by $13 \%$ [11]. Keeping this in view the government has included the infant and young child feeding practices (IYCF) in the IMNCI programme to promote and protect breastfeeding. The infant and Young Child Feeding (IYCF) guidelines state that breastfeeding should be initiated early and exclusive breastfeeding should be continued for the first 6 months of life. It is also mentioned that the most appropriate feeding strategy for infants and young children is that breastfeeding should be continued for up to 2 years and beyond with adequate complementary foods [12].

\section{Long Term Measures}

Improving quality of life, universal access to healthcare, strengthening health care systems, creating perinatal/neonatal Centers of excellence in all Government medical colleges, and leveraging the
Information technology for linking up the periphery centers with tertiary centres, creation of hospital information systems with special emphasis on maternal and neonatal care are highly essential to improve the newborn care. Empowering women, improving their literacy, reduction of poverty, and strengthening public health care system would go a long way in improving the newborn survival.

In the year 2000, the Government of India agreed to observe National Newborn Week from 15thto 21stNovember every year at the request of the National Neonatology Forum. This was a notable accomplishment in more than one way (i) it signified the recognition of newborn health as a key national priority (ii) it reflected the political commitment to the cause of newborn infants at the highest level.

Advocacy by all stake holders with missionary zeal for enhancing survival of newborns is the need of the hour and is the key to progress of the nation in the health care sector.

\section{References}

1. WHO Countdown to 2015: tracking progress in maternal, newborn \& child survival Countdown to 2015.

2. The Lancet, Volume 365, Issue 9474, Page 1845, 28 May 2005 10.1016/ S0140-6736(05)66608.

3. NRHM AP Report

4. WHO. "The Global Burden of Disease: 2004 [update (2008)]".

5. Rohini Ghosh New Delhi, India Child mortality in India: a complex situation, World J Pediatr, Vol 8 No 1, February 15, 2012 pg no 11-18.

6. Registrar General of India. Special Bulletin on Maternal Mortality in India 2007-09. Sample, Registration System, 2011; New Delhi.

7. Prakash R, Singh A, Pathak PK, Parasuraman S (2011) Early marriage, poor reproductive health status of mother and child well-being in India. J Fam Plann Reprod Health Care 37: 136-145.

8. Subramanian SV, Ackerson LK, Davey Smith G, John NA (2009) Association of maternal height with child mortality, anthropometric failure, and anemia in India. JAMA 301: 1691-1701.

9. NNF, Norms for Accreditation for Level II Special Care Neonatal Units 1991.

10. Unicef Report of assessment of Facility Based Newborn care in Andhra Pradesh-with special focus on SCNUs, 2011.

11. Jones G, Steketee RW, Black RE, Bhutta ZA, Morris SS; Bellagio Child Survival Study Group (2003) How many child deaths can we prevent this year? Lancet 362: 65-71.

12. Infant and Young Child Feeding Chapter, Indian Academy of Pediatrics, Rajeshwari K, Bang A, Chaturvedi P, et al. (2010) Infant and young child feeding guidelines: 2010. Indian Pediatr 47: 995-1004. 